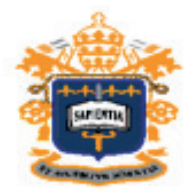

PONTIFÍCIA UNIVERSIDADE CATÓLICA DE SÃO PAULO PROGRAMA DE ESTUDOS PÓS-GRADUADOS EM ECONOMIA POLITICA GRUPO DE PESQUISAS EM ECONOMIA INDUSTRIAL, TRABALHO E TECNOLOGIA

\title{
APORTES AO \\ DESENVOLVIMENTO DA ECONOMIA BRASILEIRA
}

ORGANIZAÇÃO: ANITA KON E ELIZABETH BORELLI

SÃO PAULO

2015 


\section{Aportes ao desenvolvimento da economia brasileira}

(C) 2015

1 st edition - 2015

Editora Edgard Blücher Ltda. ISBN 978-85-8039-123-7 (e-book)

\section{Blucher}

Rua Pedroso Alvarenga, $1245,4^{\circ}$ andar

04531-012 - São Paulo - SP - Brazil

Fax 551130792707

Phone 551130785366

editora@blucher.com.br

www.blucher.com.br

Segundo o Novo Acordo Ortográfico, conforme 5a ed. do Vocabulário Ortográfico da Língua Portuguesa, Academia Brasileira de Letras, março de 2009.

É proibida a reprodução total ou parcial por quaisquer meios, sem autorização escrita da Editora.

Todos os direitos reservados pela

Editora Edgard Blucher Ltda.

\section{FICHA CATALOGRÁFICA}

Ciclo de Debates EITT (13. : 2015 : São Paulo, SP)

Aportes ao desenvolvimento da economia brasileira [livro eletrônico] / Pontifícia Universidade Católica de São Paulo -

Programa de Estudos Pós-Graduados em Economia Política ; Grupo de Pesquisas em Economia Industrial, Trabalho e Tecnologia ; organizado por Anita Kon, Elizabeth Borelli. - São Paulo : Blucher, 2015. $344 \mathrm{p}$.

ISBN 978-85-8039-123-7 (e-book)

1. Brasil - Desenvolvimento econômico 2. Economia industrial - Brasil 3. Economia política 4. Trabalho 5. Tecnologia I. Título II. Pontifícia Universidade Católica de São Paulo - Programa De Estudos Pós-Graduados em Economia Política ; III. Grupo de Pesquisas em Economia Industrial, Trabalho e Tecnologia IV. Kon, Anita V, Borelli, Elizabeth

15-1287

CDD 338.981

Índices para catálogo sistemático:

1. Brasil - Desenvolvimento econômico 


\section{APRESENTAC̣ÃO}

Esta publicação reúne ensaios apresentados e discutidos no contexto do Grupo de Pesquisas em Economia Industrial, Trabalho e Tecnologia (EITT) do Programa de Estudos Pós-Graduados em Economia Política da PUC/ $\mathrm{SP}$, que comemorou 21 anos de trabalhos consecutivos.

As atividades de pesquisa desenvolvidas pelo EITT reúnem trabalhos sobre temas relacionados às áreas que dão nome ao grupo, com o objetivo de constante atualização da análise sobre as transformações estruturais e as questões conjunturais pertinentes que se desenvolvem no mundo e especificamente no Brasil. Mais recentemente duas novas áreas foram priorizadas no contexto dos debates, tendo em vista a relevância das discussões sobre estas questões no país e a integração com as demais áreas definidas: Economia da Sustentabilidade e Economia dos Serviços. Os trabalhos do EITT incorporam uma filosofia de intercâmbio com outras instituições de ensino e pesquisa. Durante estes anos recebemos a colaboração de professores, mestrandos, doutorandos e graduandos da PUC e de outras instituições brasileiras e do exterior.

A abordagem sobre a atual Economia exige uma leitura mais ampla do que a que podíamos adotar algumas décadas atrás. A incorporação de novos cortes teóricos possibilitou a visualização de todo um sistema social produtivo, de caráter mais complexo e dinâmico. Torna-se cada vez mais factível os cruzamentos entre as relações de trabalho, o desenvolvimento industrial e dos serviços, bem como a incorporação de novas tecnologias (que muitas vezes se materializam tanto nas inovações de produto como nas inovações de processo) e ainda a relevante questão da sustentabilidade econômica e ambiental. Os desdobramentos destes fenômenos são muitos, porém os resultados induzem a uma conclusão básica: a compreensão destas variáveis exige uma análise de cunho holístico e de caráter contínuo.

A reflexão sobre os impactos da nova dinâmica na economia do país se tornou mais complexa, na medida em que, ao lado das mudanças estruturais necessárias para a busca da competitividade, as empresas tiveram a necessidade de conviver com os contundentes desequilíbrios macroeconômicos e com as políticas públicas restritivas que priorizaram a estabilização e mais recentemente com a incerteza e a queda da produção e do emprego.

As modificações no ambiente, ocorridas em função de uma evolução sistêmica dos diversos níveis institucionais já no século XXI, que tímida e gradativamente vinham se introduzindo no Brasil, conduziram a uma mudança na forma de organização nas relações inter e intrafirmas. $\bigcirc$ 
novo padrão organizacional na produção que, como sempre, soube capitalizar as modificações tecnológicas em forma de diversos tipos de redes e cadeias produtivas, acabou também por influenciar a própria lógica na localização da indústria, trazendo assim uma modificação em todas as relações subjacentes à industrialização.

Compreender toda esta dinâmica exige um esforço capaz de dar conta das diversas faces do padrão de industrialização, da incorporação do trabalho e das mudanças tecnológicas, assim como, das políticas que atuam sobre estas questões.

Estas questões relevantes do cenário de transformações recentes do país motivaram os debates em que participaram professores e mestrandos atuantes na PUCSP e também pesquisadores de várias outras instituições, convidados para apresentarem o resultado de estudos recentes e inéditos, no XIII Ciclo de Debates EITT, que compõem esta publicação. A coletânea de artigos aqui apresentada tem o objetivo de contribuir com visões diferenciadas sobre as ideias vigentes nas áreas mencionadas, em subsídio ao planejamento público e privado.

Os ensaios apresentados visam oferecer propostas de soluções para a retomada do desenvolvimento econômico sustentável, com o intuito de colaborar na formulação da criação de mecanismos institucionais e outros instrumentos e metodologias de ação. Visam, ainda, oferecer subsídios teóricos e empíricos para a melhor realocação de recursos entre setores, bem como melhor readequação da relação capital/trabalho, na direção de técnicas intensivas na absorção da força de trabalho - fator abundante em nossa economia.

Os textos abordam as discussões que se desenrolam no contexto da economia brasileira, envolvendo aspectos relativos aos recentes processos de mudanças tecnológicas e institucionais, que apresentam importantes repercussões na estrutura da indústria e do mercado de trabalho, à medida que criam e destroem empresas, empregos e mercados. Tais processos impõem a necessidade de uma constante reformulação das medidas de política econômica pública e privada, que repercutem no funcionamento da atividade produtiva e na geração de emprego.

O livro, estruturado em duas partes, apresenta na primeira as ideias que buscam enfrentar os desafios ao processo de desenvolvimento econômico, que na conjuntura de 2015 se encontra adiado, tendo em vistas os desajustes macro e microeconômicos pelos quais passa o país. São focalizadas as questões da centralidade da indústria no processo de desenvolvimento, da política pública e a prodigalidade legislativa e os acordos multilaterais da Organização Mundial do Comércio. Complementando estas visões, são discutidas questões teóricas sobre a expansão cíclica da economia 
através da demanda derivada, requerimentos de capital das instituições financeira, a sustentabilidade empresarial e a metodologia de mensuração do indicador de felicidade para o Brasil, que está sendo discutido na atualidade para outros países da ONU.

A segunda parte aborda alguns temas polêmicos na área da economia industrial, de serviços e do trabalho em textos que analisam aspectos que interferem diretamente no processo de desenvolvimento econômico, como a política macroeconômica dos anos mais recentes, a capacidade de competitividade internacional, investimentos estatais, a exploração e produção de energia e a questão relevante do papel do seguro prestamista no sistema do país. Atenção especial é dada à questão das desigualdades mercado de trabalho brasileiro, focalizando a queda da desigualdade de renda, as características da informalidade do trabalho, o perfil da mortalidade dos trabalhadores e finalmente a interpretação dos indicadores do mercado de trabalho do Brasil.

Agradecemos a valiosa colaboração dos professores e pesquisadores pelos conhecimentos novos que introduziram no ambiente de trabalhos do Grupo EITT através de suas apresentações e debates, bem como pela participação nesta publicação. 


\section{SUMÁRIO}

\section{PARTE I - DESAFIOS AO DESENVOLVIMENTO ECONÔMICO}

João Batista Pamplona (USP) e João Lucio de Azevedo Fenerich (PUCSP)

DESENVOLVIMENTO E CENTRALIDADE DA INDÚSTRIA: UMA ATUALIZAÇÃO

DO DEBATE NO BRASIL $\ldots \ldots \ldots \ldots \ldots \ldots \ldots \ldots \ldots \ldots$

Francisco Carlos Ribeiro et alii(FATEC)

POLIITICA PÚBLICA E A INTEGRAÇÃO - PRODIGALIDADE LEGISLATIVA.

PROBLEMAS PARA A POLIITICA INDUSTRIAL E DESENVOLVIMENTO

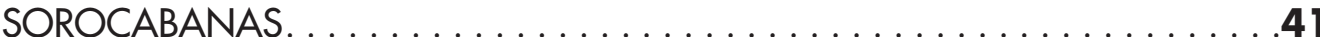

Taís Cristina de Menezes e Eduardo Luiz Machado (UNIFESP)

ENTRAVES AO ESTABELECIMENTO DE ACORDOS MULTILATERAIS NO ÂMBITO DA

OMC . . . . . . . . . . . . . . . . . . . . . . . . . . . . . . .65

Luiz Guilherme de Oliveira (UnB)

EXPANSÃO CÍCLICA DA ECONOMIA BRASILEIRA, UM RESGATE DA ABORDAGEM

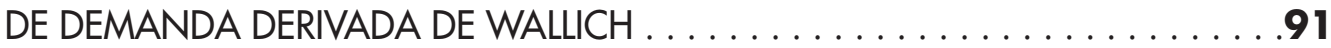

Vivian Canoas (PUCSP e INSPER)

OS IMPACTOS ECONÔMICOS DA IMPLANTAÇÃO DOS REQUERIMENTOS DE CAPITAL PARA INSTITUIÇÕES FINANCEIRAS NO MERCADO BRASILEIRO . . 101

Valério Vitor Bonelli. (PUCSP)

SUSTENTABILIDADE EMPRESARIAL ATRAVÉS DO GERENCIAMENTO ESTRATÉGICO DOS CUSTOS DE NATUREZA AMBIENTAL . 


\section{PARTE II - TEMAS POLÊMICOS DA ECONOMIA INDUSTRIAL, DE SERVIC̣OS E DO TRABALHO}

Antonio Correa de Lacerda (PUCSP)

POLÍTICA MACROECONÔMICA E INDÚSTRIA: UMA ANÁLISE DA ECONOMIA BRASILEIRA NOS ANOS LULA E DILMA, 2003-2014 . . . . . . . . . . 163

Diego Galantier (IPT) e Eduardo Luiz Machado (IPT e UNIFESP)

FATORES DETERMINANTES DA COMPETITIVIDADE INTERNACIONAL NA

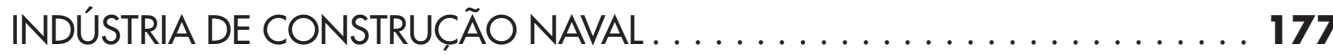

Matheus C. R. Barros (FACAMP) e Luiz M. de Niemeyer N.(PUCSP)

INVESTIMENTO ESTATAL NA INFRAESTRUTURA PORTUÁRIA BRASILEIRA . . 201

Cimar A. Prieto Aparicio (SEADE)

METODOLOGIA DE ANÁLISE ECONÔMICA REGIONAL DA EXPLORAÇÃO E PRODUÇÃO DE PETRÓLEO E GÁS NATURAL NO ESTADO DE SÃO PAULO . . 219

Fabiana Lopes da Silva. (PUCSP e FIPECAFI) e Betty L. Chan (FECAP/FIPECAFI) ANÁLISE DA DEMANDA E SINISTRALIDADE DO SEGURO PRESTAMISTA . . . $2 \mathbf{3 3}$

Maria Cristina Cacciamali, (USP), Vladimir Camilo e Fabio Tatei (USP)

QUEDA DA DESIGUALDADE DE RENDA NO BRASIL NO PERÍODO DE 2001 A 2011

Anita Kon (PUCSP)

PANORAMA DA INFORMALIDADE DO TRABALHO NO BRASIL NA VIRADA DO SÉCULO

INTERPRETANDO OS INDICADORES DO MERCADO DE TRABALHO NO BRASIL. 
